\title{
Maxillofacial Radiology 169
}

SADJ April 2019, Vol. 74 No. 3 p148

\section{CJ Nortjé}

A sixty five year old female patient (Figure $1 \&$ 2) presented at the Oral Health Centre with the main complaint of pain, swelling and stiffness of the right and left temporomandibular joints. Clinical examination revealed an anterior open bite and attrition of the posterior teeth. List your observations and give a differential diagnosis.
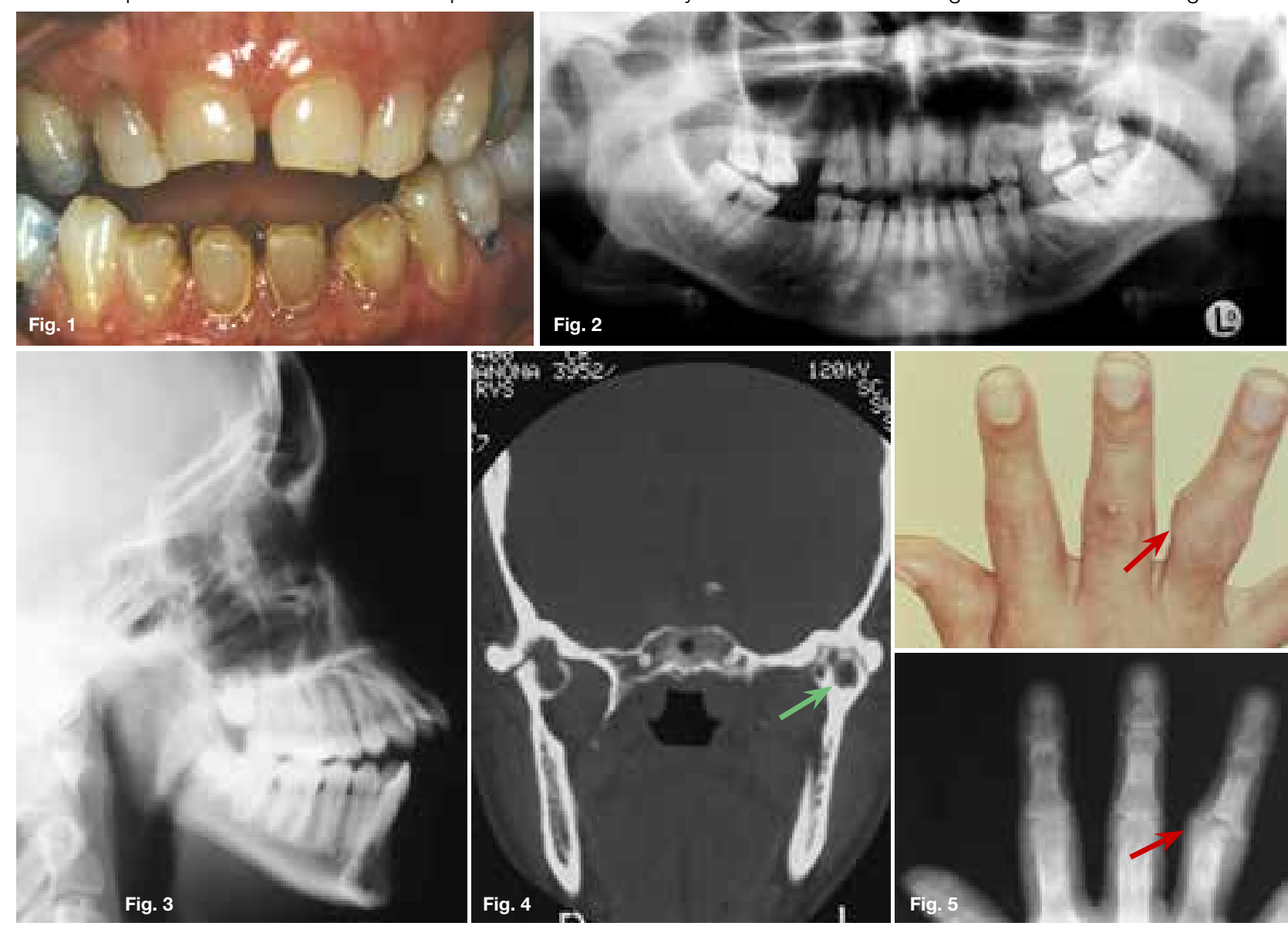

\section{INTERPRETATION}

The most important radiological observations are resorption of the articulating surfaces of the head of the condyle and articular eminence; sclerosis of the osseous components and a decrease in the size of the "joint space", an anterior open bite if one takes note that the posterior teeth are in close contact with each other and show signs of attrition. A provisional radiological diagnosis of Rheumatoid arthritis was made. Rheumatoid arthritis and related joint diseases consist of a number of inflammatory disorders that are characterized by prominent inflammation of the synovial membrane. It is a systemic disease with unknown aetiology and usually occurs within the 20-50 years age group but may occur at other ages. When it starts before the age of fifteen it is called the juvenile type of rheumatoid arthritis. Women are affected two to three times more often than men. In earlier reports the percentage figures of involvement of the temporomandibular joint were rather low, but later studies utilizing improved radiographic techniques have found involvement of the joint in from 40 to 80 per cent of cases.

CJ Nortjé: $B C h D, P h D, A B O M R$, DSc. Faculty of Dentistry, University of the Western Cape. E-mail: cnortje@uwc.ac.za
Clinically, the symptoms are usually pain and tenderness of the affected joint and stiffness or reduced mobility of the mandible. In the juvenile type, especially when the disease starts very early in life, marked growth changes may take place due to alterations in the condylar growth area. This results in the reduction of the forward and downward movement of the mandible, disto-occlusion and an anterior open bite (Figure 3). The classical clinical appearance of a bird-face may be the result of the growth changes. Radiographically, the condylar head may reveal flattening (Figure 2) or may be absent. The generalized osteoporosis may also involve the condyle, and subcondylar cysts may be formed Figure 4 (green arrow). The radiological joint changes are significantly related to the duration of the disease. Rheumatoid arthritis can affect any joint in the body, including those in the hands and fingers causing destruction of the joints Figure 5 (red arrows). The patient may experience hand pain, finger pain, swelling, and stiffness.

\section{Reference}

1. Farman AG, Nortjé CJ \& Wood R E: Oral and Maxillofacial Imaging, $1^{\text {st }}$ Ed, Mosby. St. Louis, Missouri 1993 pp. 368-9. 